\title{
Editorial: Dynamis en acceso abierto (OJS)
}

http://dx.doi.org/10.4321/S0211-95362014000100001

Están a punto de cumplirse tres años desde que el nuevo Consejo de Redacción asumió la gestión de Dynamis en mayo de 2011. Esta etapa ha estado marcada por la ilusión y por los retos que para nuestro proyecto representan la aparición regular de dos fascículos anuales, la consolidación de la plataforma RECYT como gestor editorial, las limitaciones presupuestarias derivadas de la disminución de recursos públicos destinados a la investigación y a la difusión de sus resultados y, también, por la necesidad de aumentar su visibilidad y accesibilidad en el complejo entramado digital. Retos que deben conciliarse con el mantenimiento de los niveles de calidad alcanzados por el anterior equipo de redacción dirigido por Teresa Ortiz y Jon Arrizabalaga, que situaron a Dynamis en un lugar que diversos estudios han destacado como de «visibilidad internacional muy alta» ${ }^{1}$ y elevado compromiso con la igualdad de género².

Dynamis ha consolidado en este último quinquenio su atractivo entre los profesionales de la disciplina, amén de mantenerse abierta a contribuciones desde áreas afines. Tal como pusimos de manifiesto en el XVII Simposio de la Sociedad Española de Historia de la Medicina (Santiago de Compostela, 2012), los criterios de calidad impuestos por la CNEAI y la ANECA para otorgar los sexenios de investigación y para la acreditación a plazas de profesorado, respectivamente, han contribuido a fortalecer nuestra revista como destinataria de resultados de investigación de autores que trabajan en instituciones españolas ${ }^{3}$. A ello hay

1. Román-Román, Adelaida; Giménez-Toledo, Elea. La actividad científica española en historia de la ciencia, a nivel internacional, durante el período 1990-2009. Revista Española de Documentación Científica. 2010; 33 (3): 341-377; Steinke, Hubert; Lang, Yves. Parochialism or Self-Consciousness? Internationality in Medical History Journals, 1997-2006. Medical History. 2011; 55 (4): 523-538.

2. Miqueo Miqueo, Consuelo; Germán Bes, Concha; Fernández Turrado, Teresa; Barral Morán, María José. Ellas también cuentan. Científicas en los comités de revistas biomédicas. Zaragoza: Prensas Universitarias de Zaragoza; 2011, p. 66, 271.

3. En el cómputo acumulado de trabajos publicados por la comunidad investigadora española, Dynamis aparece como la revista de la disciplina más utilizada. Osca-Lluch, Julia. La actividad científica española en historia de la ciencia, a nivel internacional, durante el periodo 19902009. In: Díaz-Rojo, José Antonio, ed. La circulación del saber científico en los siglos XIX y XX. 
que unir el atractivo que sigue ejerciendo la revista para los autores y autoras del ámbito internacional, particularmente el latinoamericano y europeo. Igualmente, hemos buscado intensificar la internacionalización de las reseñas y del proceso de evaluación de los trabajos que llegan a la redacción.

En el trienio 2009-2011 Dynamis recibió 97 originales, casi duplicando la cifra de trabajos enviados en el trienio 2003-2005, justo antes del ingreso de Dynamis en las bases de datos de la ISI-WOS. Esta tendencia al alza se ha consolidado en el bienio 2012-2013, en el que la cifra de originales recibidos asciende en el momento de confeccionar esta editorial a 106. El flujo de originales y la continuidad de las secciones monográficas han facilitado enormemente la aparición regular en primavera y otoño de los dos fascículos anuales de la revista. Las secciones monográficas incluidas en el volumen 32 (2012) compartieron una clara vocación internacional. La primera de ellas abordó el papel de la ciencia en el ordenamiento de la ciudad moderna, con ejemplos procedentes de Chile, Argentina, Brasil e Italia 4 . Las respuestas políticas y sociales y los movimientos asociativos surgidos en Europa frente a la poliomielitis, con trabajos que reflejan la experiencia sueca, italiana, británica y española, fueron el objeto del segundo monográfico del volumen ${ }^{5}$. En el volumen 33 (2013), las secciones monográficas se consagraron a temas centrados en la ciencia producida en España. El dossier publicado en el primer fascículo se dedicó a analizar las dinámicas de inclusiónexclusión social a través de los discursos y las prácticas sanitarias ${ }^{6}$. El segundo monográfico se dedicó al análisis de las estrategias que llevaron al desarrollo disciplinar de la paleontología en la España de la segunda mitad del siglo XX, a su difusión y a su internacionalización?.

Coherente con la política editorial que ha caracterizado la historia de Dynamis, el Consejo Editorial decidió en febrero de 2013 finalizar con el periodo de embargo de seis meses que preveía para el último fascículo publicado, convirtiéndose de este modo en una revista de libre y pleno acceso abierto (OJS).

Valencia: Instituto de Historia de la Medicina y de la Ciencia López Piñero; 2011, p. 183-214 (196).

4. Vallejo, Gustavo; Huertas, Rafael. La ciencia en el disciplinamiento de la ciudad moderna. Dynamis. 2012; 32 (1): 13-19.

5. Ballester, Rosa; Porras, María Isabel. La lucha europea contra la presencia epidémica de la poliomielitis: una reflexión histórica. Dynamis. 2012; 32 (2): 273-285.

6. Molero-Mesa, Jorge; Jiménez-Lucena, Isabel. (Des)legitimando jerarquías sociales, profesionales y cognitivas. Conocimiento y prácticas científicas en los procesos de inclusión-exclusión. Dynamis. 2013; 33 (1): 13-18.

7. Hochadel, Oliver. Paleoanthropology in the periphery. An introduction. Dynamis. 2013; 33 (2): 281-296. 
Las elevadas cifras de consulta en línea y descarga que nos devuelven los contadores de RACO y SciELO, nuestros repositorios digitales (a los que también se incorpora el Portal de revistas de la Universidad de Granada), evidencian la utilidad de este recurso para dar a conocer los contenidos de Dynamis sin más límite o frontera que el del acceso a la red. Más allá de la utilidad de esta medida, la decisión responde a nuestro compromiso con el movimiento de acceso abierto a la ciencia, un movimiento que desde la formalización de la «Iniciativa para el acceso abierto de Budapest» en 2002, no ha hecho más que crecer $^{8}$. En un contexto globalizado de crisis, se ha mostrado con crudeza la insostenibilidad de un modelo científico basado en la privatización de los resultados de la investigación, una privatización que afecta directamente a revistas emblemáticas de nuestra disciplina que, integradas en grandes plataformas digitales comerciales, ven seriamente comprometido el acceso digital a sus contenidos. En los últimos meses se han intensificado las llamadas sobre la necesidad de transformar las estrategias de publicación para priorizar la gratuidad del acceso digital, apelaciones realizadas incluso por las instituciones más favorecidas dentro del modelo que ha caracterizado la publicación científica en las últimas décadas. Confiamos en que este «giro por la accesibilidad» acabe alcanzando a los propios sistemas de valoración de la ciencia. En este marco, creemos en la fortaleza de un proyecto como Dynamis y confiamos en revalidar su atractivo como vehículo de prestigio para la publicación de la investigación en historia de la ciencia.

Queremos finalmente destacar otras novedades que incorporamos en este volumen. A partir de este año, acompañará a cada uno de los originales editados en Dynamis la publicación de su DOI (Digital Object Identifier), lo que facilitará la estabilidad de su identidad así como su visibilidad en la red, mejorando con ello las posibilidades de recuperación individual de los artículos a través de bases de datos y motores de búsqueda. En este fascículo acogemos un formato de trabajo que a pesar de tener una larga tradición en la historiografía, como la entrevista a profesionales de la disciplina, no habíamos publicado anteriormente en nuestra revista. Además, continuando con la política de transparencia editorial, nos hemos comprometido a incluir anualmente en nuestra web las tasas de desestimación y rechazo de originales, así como a proseguir con la publicación periódica de las listas de informantes externos que colaboran con nuestra revista.

8. Pérez Andrés, Cristina. Editorial. La revista española de salud pública con la edición electrónica y el acceso abierto a la ciencia. Revista Española de Salud Pública. 2011; 84 (6): 551-554. 